\title{
Cost-effective options for increasing consumption of under-consumed food groups and nutrients in the USA
}

\author{
Mary Brauchla ${ }^{1}$ and Victor L Fulgoni III',* \\ 'PepsiCo R\&D Nutrition, Chicago, IL, USA: ${ }^{2}$ Nutrition Impact LLC, 9275 D Drive North, Battle Creek, MI 49014, USA
}

Submitted 18 September 2020: Final revision received 18 December 2020: Accepted 27 January 2021: First published online 8 February 2021

\begin{abstract}
Objective: To identify the most cost-effective options/contributors of underconsumed food groups and nutrients in the USA.

Design: Twenty-four-hour dietary recall data were used for the dietary sources of under-consumed food groups and nutrients. Costs were estimated using USDA National Food Price Database 2001-2004 after adjustments for inflation using Consumer Price Index.

Setting: National Health and Nutrition Examination Survey, 2013-2016.

Participants: A total of 10112 adults aged 19+ years.

Results: Top five cost-effective options for food groups were apple and citrus juice, bananas, apples, and melons for fruit; baked/boiled white potatoes, mixtures of mashed potatoes, lettuce, carrots and string beans for vegetables; oatmeal, popcorn, rice, yeast breads and pasta/noodles/cooked grains for whole grain; and reduced-fat, low-fat milk, flavoured milk and cheese for dairy. Top five cost-effective sources of under-consumed nutrients were rice, tortillas, pasta/ noodles/cooked grains, rolls and buns, and peanut butter-jelly sandwiches for $\mathrm{Mg}$; grits/cooked cereals, low- and high-sugar ready-to-eat (RTE) cereal, rolls and buns, and rice for Fe; low- and high-sugar RTE cereals, rice, protein and nutritional powders, and rolls and buns for $\mathrm{Zn}$; carrots, margarine, other red and orange vegetables, liver and organ meats, butter and animal fats for vitamin A; and citrus juice, other fruit juice, vegetable juice, mustard and other condiments, and apple juice for vitamin $\mathrm{C}$.

Conclusions: Apple/citrus juice, white potatoes/carrots, oatmeal, RTE cereals and milk were the most cost-effective food sources of multiple under-consumed food groups and nutrients and can help promote healthy eating habits at minimal cost.

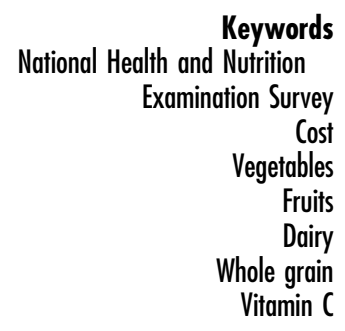

A healthy eating pattern primarily composed of fruits, vegetables, whole grains and low-fat dairy has been consistently recommended by the Dietary Guidelines for Americans (DGA) and other organisations ${ }^{(1-3)}$. Specific food group intake recommendations are provided in ChooseMyPlate $^{(4)}$, and the USDA has also developed several food patterns that meet energy and food group recommendations for individuals with specific dietary needs or preferences (e.g. vegetarians) ${ }^{(5)}$. However, there is still a wide gap between food group recommendations and consumption: more than three-quarters of the US population currently do not meet daily intake recommendation for fruits (nearly $80 \%$ ), vegetables (nearly $90 \%$ ), whole grains (nearly $100 \%$ ) and dairy (nearly $80 \%)^{(1)}$.

These gaps between recommended and actual food group consumption are significant because they translate to inadequate intakes of several essential nutrients. The 2015-2020 DGA ${ }^{(1)}$ identified several nutrients as 'underconsumed' including vitamin A, vitamin D, vitamin E, vitamin C, Ca, Fe (for certain age/gender groups), Mg, choline, $\mathrm{K}$, and fibre; four of these nutrients ( $\mathrm{Ca}$, vitamin $\mathrm{D}, \mathrm{K}$ and fibre) are classified as 'nutrients of public health concern' because intake at low levels is associated with adverse health outcomes. Many of these under-consumed nutrients are primarily found in fruits, vegetables, whole grains, and dairy, and previous public health messaging has promoted higher intakes of these food groups to close nutrient gaps.

Despite targeted public health messaging around these food groups intake remains well below the recommended levels ${ }^{(1)}$. The reasons underlying low food group intakes are multifactorial, but one contributor is the economic impact of choosing 'healthier' foods ${ }^{(6-8)}$. Food purchase 
decisions are often driven by food cost, which makes cost a major determinant of dietary intakes ${ }^{(8-10)}$. Rao et al ${ }^{(11)} \mathrm{Con}-$ ducted a meta-analysis and systematic review of twentyseven studies and reported that healthier dietary patterns cost about $\$ 1.50$ more per day ( $\$ 550$ more per year) compared to less healthy dietary patterns. In a recent analysis, we estimated that the USDA's Healthy Food Patterns are generally more expensive than current US $\operatorname{diet}^{(12)}$. Additional studies have also come to the same conclusions: higher diet quality diets cost more and are associated with higher spending ${ }^{(13-16)}$. Therefore, there is a clear need for more solution-oriented research to identify low-cost healthier dietary options for low socio-economic status individuals and budget-conscious shoppers.

In a recently published analysis, we compared the cost of obtaining 'shortfall nutrients' including nutrients of public health concern (dietary fibre, vitamin D, Ca and K) from different food groups to identify cost-effective options for healthy and sustainable eating patterns for Americans ${ }^{(17)}$. The present analysis builds on our previous work by identifying the most cost-effective contributors to underconsumed food groups and additional nutrients in the USA.

\section{Methods}

\section{Database and subjects}

Data from What We Eat in America (WWEIA), the dietary component of the National Health and Nutrition Examination Survey (NHANES), were used ${ }^{(18)}$. NHANES is a continuous, nationally representative, cross-sectional survey of non-institutionalised, civilian US population conducted by the National Center for Health Statistics (NCHS) using a complex, multistage, probability sampling design, and the data are released in 2-year cycles. The present analysis combined two NHANES data cycles (NHANES 2013-2014 and NHANES 2015-2016). Day one 24-h dietary recall data from adults aged $19+$ years ( $n 10$ 112) excluding pregnant and/or lactating females ( $n$ 218) and those with incomplete or unreliable dietary records as evaluated by the USDA Food Surveys Research Group staff ( $n$ 1461) were included in the analysis.

\section{Estimation of dietary intake}

Dietary intake data were obtained via in-person 24-h dietary recall interviews administered using an Automated Multiple-Pass Method ${ }^{(19)}$. To determine food sources of food groups (fruits, vegetables, whole grains and dairy) and under-consumed nutrients $(\mathrm{Mg}, \mathrm{Fe}, \mathrm{Zn}$, vitamin $\mathrm{A}$ and vitamin C), USDA's WWEIA food groups were used at food main group ( $n$ 15), food subgroup ( $n$ 48) and food category ( $n$ 155) level ${ }^{(20)}$. Food category 'Baby foods' were excluded from the analysis, since the current analysis was focused on the adult population. Intake and composition of food groups were calculated using the NHANES cyclespecific Food Patterns Equivalents Databases (FPED) ${ }^{(21)}$.
Nutrient intake and composition were determined using the respective Food \& Nutrient Database for Dietary Studies (FNDDS) for each NHANES cycle ${ }^{(22)}$.

\section{Estimation of food cost}

The USDA National Food Price Database (NFPD) was used to estimate cost of foods and nutrients from foods and beverages. The NFPD is derived from the Nielsen Homescan Consumer Panel and provides costs of all foods and beverages in NHANES 2001-2004 $4^{(23,24)}$. Food cost for 2013-2016 was computed after adjusting the base food cost for inflation from 2001-2004 to 2013-2016 using Consumer Price Index (CPI) data from Bureau of Labor Statistics (BLS) ${ }^{(25)}$ as described previously ${ }^{(12,17)}$. The prices for foods and beverages were calculated per cup equivalent for dairy, fruits and vegetables, per ounce equivalent for whole grains, and per $g$, mg or $\mu \mathrm{g}$ for nutrients. NHANES food codes for 20132016 cycles were matched to NHANES 2001-2004 and then linked with NFPD to estimate base food cost. New food codes in NHANES 2013-2016 that were not present in NHANES 2001-2004 were hand-matched to the most closely matching food code. Cost-effectiveness was evaluated as amounts food groups and nutrients available per dollar.

\section{Statistics}

All statistical analyses were performed with SAS software (version 9.4; SAS Institute Inc.). Data were adjusted for the complex sample design of NHANES using appropriate survey weights, strata, primary sampling units and day one dietary sample weights.

\section{Results}

The top five cost-effective options for fruit were apple juice, citrus juice, bananas, apples and melons providing 2.734.20 cup equivalents per dollar. Except for apple juice, these were also the top contributors of daily intake of fruit. Together, the top five cost-effective options contributed $54 \cdot 8 \%(2 \cdot 67 \%+13 \cdot 6 \%+12 \cdot 6 \%+17 \cdot 8 \%+8 \cdot 11 \%$ contribution from apple juice, citrus juice, bananas, apples and melons, respectively) of daily intake of fruit (Table 1).

Baked or boiled white potatoes, mixtures of mashed potatoes and white potato, lettuce, carrots, and string beans were top five cost-effective options for vegetables providing 2.45-3.71 cup equivalents per dollar. Together these contributed about $22.2 \%$ of daily intake of vegetables (Table 1).

For whole grain, the top five cost-effective options were oatmeal, popcorn, rice, yeast breads and pasta/noodles/ cooked grains providing 3.06-5.13 ounce equivalents per dollar. Yeast bread was the top contributor of whole grain and provided $32.9 \%$ of daily intake. The top five costeffective options of whole grain combined contributed to $53.6 \%$ of total daily intake (Table 1 ). 
Table 1 Top ten cost-effective contributors of under-consumed food groups and their contribution to current intake*

\begin{tabular}{|c|c|c|c|c|c|c|c|c|}
\hline \multirow[b]{2}{*}{ Category no } & \multirow[b]{2}{*}{ Category } & \multirow[b]{2}{*}{$n$} & \multirow{2}{*}{$\begin{array}{c}\text { Rank by } \\
\text { cost } \dagger\end{array}$} & \multicolumn{2}{|c|}{$\begin{array}{l}\text { Cost-effectiveness } \\
\text { (units of food group/ } \\
\text { dollar) } \ddagger \\
\end{array}$} & \multicolumn{2}{|c|}{$\begin{array}{l}\% \text { Contribution } \\
\text { to daily intake } \\
\text { of food group }\end{array}$} & \multirow{2}{*}{$\begin{array}{l}\text { Rank by \% } \\
\text { daily intake } \\
\text { of food group }\end{array}$} \\
\hline & & & & Mean & SE & Mean & SE & \\
\hline \multicolumn{9}{|c|}{ Food group: total fruits (cup eq) } \\
\hline 7004 & Apple juice & 241 & 1 & $4 \cdot 20$ & 0.01 & $2 \cdot 67$ & 0.41 & 11 \\
\hline 7002 & Citrus juice & 1069 & 2 & $4 \cdot 19$ & 0.07 & $13 \cdot 6$ & 0.6 & 2 \\
\hline 6004 & Bananas & 1432 & 3 & 3.45 & 0.002 & $12 \cdot 6$ & 0.6 & 3 \\
\hline 6002 & Apples & 1100 & 4 & 2.95 & 0.01 & $17 \cdot 8$ & 0.8 & 1 \\
\hline 6014 & Melons & 489 & 5 & 2.73 & 0.07 & $8 \cdot 11$ & 0.87 & 4 \\
\hline 7006 & Other fruit juice & 498 & 6 & 2.59 & 0.04 & $5 \cdot 85$ & 0.58 & 7 \\
\hline 6016 & Dried fruits & 321 & 7 & 1.95 & 0.16 & 1.75 & 0.18 & 13 \\
\hline 6008 & Peaches and nectarines & 284 & 8 & 1.86 & 0.08 & 2.44 & 0.36 & 12 \\
\hline 6006 & Grapes & 480 & 9 & 1.85 & 0.001 & 3.55 & 0.29 & 10 \\
\hline 7220 & Smoothies and grain drinks & 379 & 10 & 1.44 & 0.06 & 5.98 & 0.66 & 6 \\
\hline \multicolumn{9}{|c|}{ Food group: total vegetables excluding legumes (cup eq) } \\
\hline 6802 & White potatoes, baked or boiled & 476 & 1 & $3 \cdot 71$ & 0.08 & 4.06 & 0.36 & 8 \\
\hline 6806 & Mashed potatoes and white potato mixtures & 793 & 2 & $3 \cdot 16$ & 0.07 & $5 \cdot 81$ & 0.46 & 4 \\
\hline 6410 & Lettuce and lettuce salads & 2137 & 3 & 2.91 & 0.04 & $7 \cdot 47$ & 0.36 & 2 \\
\hline 6404 & Carrots & 681 & 4 & $2 \cdot 72$ & 0.01 & $2 \cdot 39$ & 0.29 & 16 \\
\hline 6412 & String beans & 450 & 5 & 2.45 & 0.04 & $2 \cdot 52$ & 0.25 & 15 \\
\hline 6414 & Onions & 929 & 6 & $2 \cdot 36$ & $0 \cdot 10$ & $1 \cdot 10$ & 0.06 & 26 \\
\hline 5002 & Potato chips & 1262 & 7 & 1.78 & 0.02 & $4 \cdot 82$ & 0.22 & 6 \\
\hline 6804 & French fries and other fried white potatoes & 1586 & 8 & 1.78 & 0.04 & $6 \cdot 73$ & 0.25 & 3 \\
\hline 6422 & Vegetable mixed dishes & 525 & 9 & 1.73 & 0.13 & 3.48 & 0.27 & 12 \\
\hline 7008 & Vegetable juice & 119 & 10 & 1.72 & 0.20 & 0.90 & 0.13 & 29 \\
\hline \multicolumn{9}{|c|}{ Food group: whole grain (oz eq) } \\
\hline 4802 & Oatmeal & 575 & 1 & $5 \cdot 13$ & 0.10 & $8 \cdot 50$ & 0.52 & 4 \\
\hline 5006 & Popcorn & 492 & 2 & 4.45 & 0.14 & $5 \cdot 67$ & 0.34 & 6 \\
\hline 4002 & Rice & 1558 & 3 & 3.52 & 0.25 & $4 \cdot 31$ & 0.53 & 7 \\
\hline 4202 & Yeast breads & 3636 & 4 & $3 \cdot 27$ & 0.12 & $32 \cdot 9$ & 1.0 & 1 \\
\hline 4004 & Pasta, noodles, cooked grains & 296 & 5 & 3.06 & 0.63 & $2 \cdot 18$ & 0.45 & 10 \\
\hline 4604 & Ready-to-eat cereal, lower sugar $(\leq 21.2 \mathrm{~g} / 100 \mathrm{~g})$ & 806 & 6 & $2 \cdot 40$ & 0.13 & $9 \cdot 67$ & 0.55 & 2 \\
\hline 3722 & Peanut butter and jelly sandwiches (single code) & 110 & 7 & 2.04 & 0.24 & 1.00 & 0.18 & 17 \\
\hline 4602 & Ready-to-eat cereal, higher sugar (>21.2 g/100 g) & 962 & 8 & 2.03 & 0.06 & 8.93 & 0.52 & 3 \\
\hline 5004 & Tortilla, maize, other chips & 1268 & 9 & 1.36 & 0.11 & $6 \cdot 69$ & 0.59 & 5 \\
\hline 3720 & Cheese sandwiches (single code) & 72 & 10 & $1 \cdot 30$ & 0.37 & 0.55 & 0.10 & 20 \\
\hline \multicolumn{9}{|c|}{ Food group: total dairy (cup eq) } \\
\hline 1004 & Milk, reduced fat & 1467 & 1 & 4.50 & 0.02 & 11.0 & 0.7 & 2 \\
\hline 1006 & Milk, low fat & 421 & 2 & 4.48 & 0.02 & $3 \cdot 12$ & 0.24 & 7 \\
\hline 1206 & Flavoured milk, low fat & 32 & 3 & $2 \cdot 81$ & 0.12 & 0.48 & 0.14 & 34 \\
\hline 1204 & Flavoured milk, reduced fat & 92 & 4 & $2 \cdot 60$ & 0.09 & 0.78 & 0.12 & 23 \\
\hline 1602 & Cheese & 3150 & 5 & $2 \cdot 35$ & 0.03 & $21 \cdot 2$ & 0.7 & 1 \\
\hline 1008 & Milk, non-fat & 436 & 6 & $2 \cdot 34$ & 0.01 & $4 \cdot 17$ & 0.40 & 6 \\
\hline 1002 & Milk, whole & 1010 & 7 & $2 \cdot 24$ & 0.02 & $6 \cdot 90$ & 0.65 & 4 \\
\hline 1202 & Flavoured milk, whole & 85 & 8 & 2.08 & 0.08 & 0.63 & 0.21 & 28 \\
\hline 3720 & Cheese sandwiches (single code) & 72 & 9 & 1.99 & 0.03 & 0.49 & 0.07 & 33 \\
\hline 1402 & Milk shakes and other dairy drinks & 127 & 10 & 1.71 & 0.09 & 1.21 & 0.20 & 20 \\
\hline
\end{tabular}

$n$, number of consumers; NHANES, National Health and Nutrition Examination Survey.

*Data from NHANES 2013-2016 for adults aged 19+ years.

†Ranking of foods from most cost-effective to least cost-effective source.

$\ddagger$ Cost-effectiveness was evaluated as amount of food group available per dollar; \% contribution to daily intake of food group was calculated as intake of a food group from an individual food source/total daily intake of that food group from all dietary sources $\times 100$.

Reduced-fat milk, low-fat milk, low-fat flavoured milk, reduced-fat flavoured milk and cheese were top five cost-effective options for dairy providing $2 \cdot 35-4 \cdot 50$ cup equivalents per dollar. Cheese and reduced-fat milk were also the top two contributors of dairy and provided $21.2 \%$ and $11.0 \%$ of daily intake, respectively. The remaining three of the top five cost-effective options for dairy combined contributed to less than $5 \%$ of total daily intake (Table 1).

Rice and rolls/buns were among the top five costeffective sources for $\mathrm{Mg}$, Fe and $\mathrm{Zn}$, while high- and low-sugar ready-to-eat (RTE) cereals were also among the top five cost-effective sources of Fe and $\mathrm{Zn}$ and among the top ten for vitamin A. Oatmeal, the top cost-effective option for whole grains, was also among the top ten cost-effective contributors of $\mathrm{Mg}, \mathrm{Fe}, \mathrm{Zn}$, and vitamin $\mathrm{A}$. Other top five cost-effective sources of these minerals were tortillas, pasta/noodles/cooked grains and peanut butterjelly sandwiches for $\mathrm{Mg}$; grits for $\mathrm{Fe}$; and protein/nutritional powders for $\mathrm{Zn}$. The top five cost-effective sources of these minerals were relatively minor sources (except RTE cereals for Fe and $\mathrm{Zn}$ ) and contributed to $3.79 \%$ of daily $\mathrm{Mg}, 19.3 \%$ 
of daily Fe, and $10.5 \%$ of daily Zn. High- and low-sugar RTE cereals provided $14.8 \%$ of daily Fe and $7.36 \%$ of daily $\mathrm{Zn}$ (Table 2).

Carrots, margarine, other red and orange vegetables, liver and organ meats, butter and animal fats were the top five cost-effective sources of vitamin A; and citrus juice, other fruit juice, vegetable juice, mustard and other condiments, and apple juice were the top five cost-effective sources for vitamin C. Carrots and citrus juice were also the top dietary contributors of vitamin A and vitamin C, providing $6.21 \%$ and $13.4 \%$ of daily intakes, respectively. The other top five cost-effective sources (rank 2-5) of vitamin A and vitamin $\mathrm{C}$ were minor contributors and together provided $7.07 \%$ and $9.11 \%$ of their respective daily intakes (Table 2).

Oatmeal, the top cost-effective option for whole grains was also among the top ten cost-effective contributors of $\mathrm{Mg}, \mathrm{Fe}, \mathrm{Zn}$ and vitamin A. Similarly, RTE cereals were also among the top ten cost-effective contributors of Fe, $\mathrm{Zn}$ and vitamin $\mathrm{A}$, in addition to being among top five cost-effective options for whole grain. Milk, in addition to being the top cost-effective option for dairy, was among the top ten costeffective contributors of $\mathrm{Zn}$ and vitamin A while carrots, the fourth most cost-effective option for vegetables, was the top cost-effective contributor of vitamin A. Citrus juice was the second most cost-effective option for fruit and the most cost-effective source of vitamin C (Tables 1 and 2).

\section{Discussion}

In the present analysis of NHANES 2013-2016 using a recent nationally representative sample of US adults, the most cost-effective sources of fruits, vegetables, whole grains and dairy were apple juice, white potatoes, oatmeal and reduced-fat milk, respectively. To the best of our knowledge, this is the first analysis of nationally representative, non-institutionalised population of US adults identifying the cost-effective contributors to key food groups. Additionally, in the present analysis, rice, grits and cooked cereals, RTE cereals, carrots, and citrus juice were the most cost-effective sources of $\mathrm{Mg}, \mathrm{Fe}, \mathrm{Zn}$, vitamin A and vitamin $\mathrm{C}$, respectively.

Numerous studies comparing the cost of foods and diets have indicated that healthier options cost more than less healthy options ${ }^{(11-16)}$. Cost of food is a major factor in food choice and has therefore been a significant barrier to healthy eating, especially among low socio-economic groups $^{(26-28)}$. However, few studies have compared the cost of different foods or identified lower cost options for under-consumed food groups or nutrients.

Previous research identified potatoes and beans as the lowest-cost sources of $\mathrm{K}$ and fibre among frequently consumed vegetables ${ }^{(29)}$. In addition, our results suggest that potatoes are the most cost-effective source of vegetables and more than twofold less expensive than the most consumed vegetable option 'other vegetables and combinations' (3.71 v. 1.68 cups equivalents per dollar). For whole grains and dairy, the most cost-effective contributors were oatmeal and reduced-fat milk which were $36 \%$ and $48 \%$ less expensive, respectively, than the most common dietary sources of whole grains and dairy, namely bread and cheese. In the present analysis, the most cost-effective food sources of under-consumed minerals $\mathrm{Mg}, \mathrm{Fe}$ and $\mathrm{Zn}$ were also less expensive than their respective most common dietary sources. In a dietary modelling study aimed to eliminate shortfall of fruit intake among children of 4-18 years old, a combination of $100 \%$ fruit juice + whole fruit was found to be $4.3 \%$ less expensive option than whole fruit alone ${ }^{(30)}$. In the present study, we found that apple juice was the most cost-effective source of fruit intake and was about $30 \%$ less expensive ( $42 \%$ more fruit cup eq per dollar) than apples, the top dietary source of fruit.

Foods such as oatmeal, RTE cereals, milk, carrots and citrus juice were among the most cost-effective food sources of multiple under-consumed food groups and nutrients. The present analysis shows that per dollar, oatmeal provides $5 \mathrm{oz}$ eq ( $>100 \%$ of daily recommended amount) of whole grain, $221 \mathrm{mg}$ ( $>50 \%$ RDA) of $\mathrm{Mg}$, $14 \mathrm{mg}(>75 \% \mathrm{RDA})$ of $\mathrm{Fe}, 5.6 \mathrm{mg}(>50 \% \mathrm{RDA})$ of $\mathrm{Zn}$ and $556 \mu \mathrm{g}$ retinol activity equivalents (RAE) (>60\% RDA) of Zn along with other nutrients. Similarly, for each dollar spent, RTE cereals provide $>2 \mathrm{oz}$ eq whole grain (>50\% of daily recommended amount), $33 \mathrm{mg}$ (>100\% RDA) of Fe, $>10 \mathrm{mg}$ ( $>90 \% \mathrm{RDA}$ ) of $\mathrm{Zn}$ and $800 \mu \mathrm{g}$ RAE ( $>85 \% \mathrm{RDA}$ ) of vitamin A; and milk provided 4.5 cups eq $(>100 \%$ of daily recommended amount) of dairy, $>5 \mathrm{mg}(>40 \% \mathrm{RDA})$ of $\mathrm{Zn}$ and $>600 \mu \mathrm{g} \mathrm{RAE}(>60 \%$ RDA) of vitamin A. Additionally, these foods are meaningful sources of other key nutrients not analysed in this report. These foods could easily be included (if not already in) in the USDA's Thrifty Food Plan (TFP) which is the national standard for minimal cost diet to help meet dietary recommendations and serves as the basis for the allotment of Supplemental Nutrition Assistance Program (SNAP) benefits $^{(30)}$. The average American family spends about $25 \%$ more on foods than in the TFP and even low-income families spend more than the TFP, highlighting the importance of communicating low-cost food and beverage options to both low SES and budget-conscious shoppers.

This study has several strengths and limitations. Using a large, nationally representative database to estimate nutrient cost is a major strength of the present study. However, using self-reported 24-h dietary recall data may be a limitation, as it is subject to over- or under-reporting and may not provide a true picture of usual eating habits. The USDA NFPD assumes that all foods were purchased at retail and prepared at home, restaurant prices were not included, and may not reflect seasonal, geographic/location-related differences in food price/diet cost. Some food codes in NHANES 2013-2016 had to be hand-matched to the closest 
Table 2 Top ten cost-effective contributors of under-consumed nutrients and their contribution to current daily intake*

\begin{tabular}{|c|c|c|c|c|c|c|c|c|}
\hline \multirow[b]{2}{*}{ Categoryno } & \multirow[b]{2}{*}{ Category } & \multirow[b]{2}{*}{$n$} & \multirow{2}{*}{$\begin{array}{c}\text { Rank by } \\
\text { cost } †\end{array}$} & \multicolumn{2}{|c|}{$\begin{array}{c}\text { Cost-effective- } \\
\text { ness (units of } \\
\text { nutrient/dollar) } \ddagger \\
\end{array}$} & \multicolumn{2}{|c|}{$\begin{array}{c}\% \text { Contribution } \\
\text { to daily intake } \\
\text { of nutrients } \\
\end{array}$} & \multirow{2}{*}{$\begin{array}{l}\text { Rank by } \% \\
\text { daily intake } \\
\text { of nutrient }\end{array}$} \\
\hline & & & & Mean & SE & Mean & SE & \\
\hline \multicolumn{9}{|c|}{ Nutrient: $\mathrm{Mg}(\mathrm{mg})$} \\
\hline 4002 & Rice & 1558 & 1 & $301 \cdot 0$ & $4 \cdot 0$ & 1.09 & 0.09 & 28 \\
\hline 4208 & Tortillas & 864 & 2 & $279 \cdot 0$ & $39 \cdot 0$ & 1.02 & $0 \cdot 13$ & 33 \\
\hline 4004 & Pasta, noodles, cooked grains & 296 & 3 & $236 \cdot 0$ & $25 \cdot 0$ & 0.50 & 0.06 & 61 \\
\hline 4204 & Rolls and buns & 1327 & 4 & $235 \cdot 0$ & $18 \cdot 0$ & 0.84 & 0.05 & 44 \\
\hline 3722 & Peanut butter and jelly sandwiches (single code) & 110 & 5 & $234 \cdot 0$ & $4 \cdot 0$ & 0.34 & 0.04 & 79 \\
\hline 4802 & Oatmeal & 575 & 6 & $221 \cdot 0$ & $6 \cdot 0$ & 1.08 & 0.07 & 29 \\
\hline 2802 & Beans, peas, legumes & 1166 & 7 & $220 \cdot 0$ & $9 \cdot 0$ & 1.93 & $0 \cdot 14$ & 11 \\
\hline 9802 & Protein and nutritional powders & 183 & 8 & $217 \cdot 0$ & $16 \cdot 0$ & 1.39 & 0.21 & 18 \\
\hline 2804 & Nuts and seeds & 1744 & 9 & $181 \cdot 0$ & $4 \cdot 0$ & $6 \cdot 31$ & 0.38 & 1 \\
\hline 5006 & Popcorn & 492 & 10 & $179 \cdot 0$ & $6 \cdot 0$ & 0.67 & 0.05 & 50 \\
\hline \multicolumn{9}{|c|}{ Nutrient: $\mathrm{Fe}(\mathrm{mg})$} \\
\hline 4804 & Grits and other cooked cereals & 230 & 1 & $35 \cdot 8$ & $5 \cdot 5$ & 0.62 & $0 \cdot 10$ & 43 \\
\hline 4604 & Ready-to-eat cereal, lower sugar ( $\leq 21.2 \mathrm{~g} / 100 \mathrm{~g})$ & 806 & 2 & 33.0 & 1.9 & $8 \cdot 39$ & 0.41 & 1 \\
\hline 4204 & Rolls and buns & 1327 & 3 & 31.5 & $2 \cdot 2$ & $2 \cdot 41$ & 0.12 & 10 \\
\hline 4602 & Ready-to-eat cereal, higher sugar (>21.2 g/100 g) & 962 & 4 & $23 \cdot 0$ & 0.8 & $6 \cdot 39$ & 0.26 & 2 \\
\hline 4002 & Rice & 1558 & 5 & $19 \cdot 6$ & 0.6 & 1.51 & 0.13 & 18 \\
\hline 4802 & Oatmeal & 575 & 6 & 13.7 & 0.4 & 1.43 & $0 \cdot 10$ & 19 \\
\hline 4208 & Tortillas & 864 & 7 & $11 \cdot 0$ & 1.5 & 0.86 & $0 \cdot 10$ & 31 \\
\hline 5204 & Saltine crackers & 339 & 8 & $10 \cdot 1$ & 0.4 & 0.23 & 0.02 & 83 \\
\hline 4004 & Pasta, noodles, cooked grains & 296 & 9 & $9 \cdot 85$ & 0.52 & 0.44 & 0.04 & 55 \\
\hline 2802 & Beans, peas, legumes & 1166 & 10 & $9 \cdot 84$ & 0.43 & 1.85 & 0.13 & 14 \\
\hline \multicolumn{9}{|c|}{ Nutrient: Zn (mg) } \\
\hline 4602 & Ready-to-eat cereal, higher sugar (>21.2 g/100 g) & 962 & 1 & $11 \cdot 4$ & 0.4 & 4.02 & 0.20 & 3 \\
\hline 4604 & Ready-to-eat cereal, lower sugar $(\leq 21.2 \mathrm{~g} / 100 \mathrm{~g})$ & 806 & 2 & $10 \cdot 3$ & 0.8 & $3 \cdot 34$ & 0.20 & 7 \\
\hline 4002 & Rice & 1558 & 3 & $9 \cdot 62$ & 0.19 & 0.95 & 0.08 & 26 \\
\hline 9802 & Protein and nutritional powders & 183 & 4 & 7.86 & 0.59 & 1.38 & 0.21 & 20 \\
\hline 4204 & Rolls and buns & 1327 & 5 & $7 \cdot 39$ & 0.52 & 0.72 & 0.04 & 34 \\
\hline 3702 & Burgers (single code) & 654 & 6 & $6 \cdot 57$ & $0 \cdot 10$ & $3 \cdot 20$ & 0.22 & 9 \\
\hline 4802 & Oatmeal & 575 & 7 & $5 \cdot 60$ & 0.20 & $0 \cdot 74$ & 0.05 & 33 \\
\hline 4004 & Pasta, noodles, cooked grains & 296 & 8 & 5.48 & 0.41 & 0.31 & 0.04 & 71 \\
\hline 4208 & Tortillas & 864 & 9 & 5.47 & 0.73 & 0.55 & 0.07 & 53 \\
\hline 1004 & Milk, reduced fat & 1467 & 10 & $5 \cdot 24$ & 0.03 & 1.79 & $0 \cdot 12$ & 16 \\
\hline \multicolumn{9}{|c|}{ Nutrient: vitamin A, RAE (mcg) } \\
\hline 6404 & Carrots & 681 & 1 & $2910 \cdot 0$ & 22 & $6 \cdot 21$ & 0.76 & 1 \\
\hline 8004 & Margarine & 787 & 2 & $2309 \cdot 0$ & $53 \cdot 0$ & 1.33 & $0 \cdot 12$ & 26 \\
\hline 6406 & Other red and orange vegetables & 314 & 3 & $1942 \cdot 0$ & $108 \cdot 0$ & 3.58 & 0.36 & 7 \\
\hline 2010 & Liver and organ meats & 49 & 4 & $1682 \cdot 0$ & $679 \cdot 0$ & 0.79 & 0.31 & 37 \\
\hline 8002 & Butter and animal fats & 986 & 5 & $807 \cdot 0$ & $10 \cdot 0$ & 1.37 & 0.09 & 23 \\
\hline 4602 & Ready-to-eat cereal, higher sugar (>21.2 g/100 g) & 962 & 6 & $801 \cdot 0$ & $24 \cdot 0$ & $5 \cdot 02$ & 0.26 & 4 \\
\hline 7008 & Vegetable juice & 119 & 7 & 734.0 & $89 \cdot 0$ & 0.93 & 0.20 & 35 \\
\hline 1006 & Milk, low fat & 421 & 8 & $634 \cdot 0$ & $4 \cdot 0$ & 1.09 & 0.09 & 30 \\
\hline 1004 & Milk, reduced fat & 1467 & 9 & $602 \cdot 0$ & $3 \cdot 0$ & $3 \cdot 65$ & 0.25 & 6 \\
\hline 4802 & Oatmeal & 575 & 10 & $576 \cdot 0$ & $28 \cdot 0$ & 1.36 & $0 \cdot 12$ & 24 \\
\hline \multicolumn{9}{|c|}{ Nutrient: vitamin C (mg) } \\
\hline 7002 & Citrus juice & 1069 & 1 & $359 \cdot 0$ & $5 \cdot 0$ & 13.4 & 0.6 & 1 \\
\hline 7006 & Other fruit juice & 498 & 2 & $186 \cdot 0$ & $5 \cdot 0$ & 4.86 & 0.45 & 6 \\
\hline 7008 & Vegetable juice & 119 & 3 & $182 \cdot 0$ & 33.0 & 1.85 & 0.28 & 13 \\
\hline 8406 & Mustard and other condiments & 1470 & 4 & $148 \cdot 0$ & $17 \cdot 0$ & 1.50 & 0.20 & 19 \\
\hline 7004 & Apple juice & 241 & 5 & $123 \cdot 0$ & $6 \cdot 0$ & 0.90 & 0.15 & 31 \\
\hline 7204 & Fruit drinks & 1267 & 6 & $116 \cdot 0$ & $7 \cdot 0$ & $6 \cdot 68$ & 0.38 & 3 \\
\hline 6406 & Other red and orange vegetables & 314 & 7 & $102 \cdot 0$ & $15 \cdot 0$ & 1.51 & 0.31 & 18 \\
\hline 6408 & Dark green vegetables, excluding lettuce & 970 & 8 & $78 \cdot 0$ & $2 \cdot 7$ & $5 \cdot 62$ & 0.48 & 4 \\
\hline 7804 & Enhanced or fortified water & 65 & 9 & $72 \cdot 8$ & 3.5 & 0.82 & 0.14 & 32 \\
\hline 9999 & Not included in a food category & 244 & 10 & 69.9 & 31.4 & 0.21 & 0.11 & 60 \\
\hline
\end{tabular}

$n$, number of consumers; NHANES, National Health and Nutrition Examination Survey; RAE, retinol activity equivalents.

*Data from NHANES 2013-2016 for adults aged 19+ years.

†Ranking of foods from most cost-effective to least cost-effective source.

$\ddagger$ Cost-effectiveness was evaluated as amount of a nutrient available per dollar; \% contribution to daily intake of nutrient was calculated as intake of a nutrient from an individual

food source/total daily intake of that nutrient from all dietary sources $\times 100$. 
available food codes in NHANES 2001-2004 database, and this process may have introduced inaccuracies in cost estimations. Additionally, there may be inaccuracies in the adjustment for inflation, based on CPI/BLS food categories as price differentials within a category would not have been captured.

In conclusion, apple/citrus juice, white potatoes/ carrots, oatmeal, RTE cereals and milk were the most cost-effective food sources of multiple under-consumed food groups and nutrients. This information should be included in dietary recommendations to ensure healthy eating habits at minimal cost to the consumer.

\section{Acknowledgements}

Acknowledgements: The views expressed in this manuscript are those of the authors and do not necessarily reflect the position or policy of PepsiCo Inc. Financial support: The present research was funded and supported by PepsiCo Inc. Conflict of interest: Mary Brauchla is an employee of PepsiCo, Inc., which manufactures oatmeal products under the brand name Quaker Oats ${ }^{\circledR}$ and juice under the names Tropicana ${ }^{\circledR}$, Naked ${ }^{\circledR}$ and Dole ${ }^{\circledR}$. Victor L. Fulgoni, III, as Senior Vice-President of Nutrition Impact, provides food and nutrition consulting services for food and beverage companies. Authorship: V.L.F., III conceptualised the study, conducted the final NHANES database analyses, interpreted the data, drafted the initial manuscript, and reviewed and revised the manuscript. M.B. conceptualised the study, interpreted the data, and reviewed and revised the manuscript. All authors approved the final manuscript version of the present research and agree to be accountable for all aspects of the work. Ethics of buman subject participation: This study was conducted according to the guidelines laid down in the Declaration of Helsinki, and all procedures involving research study participants were approved by the Research Ethics Review Board at the National Center for Health Statistics. Written informed consent was obtained from all subjects/patients.

\section{References}

1. U.S. Department of Health and Human Services \& U.S. Department of Agriculture (2015) 2015-2020 Dietary guidelines for Americans. 8th edition. http://health.gov/ dietaryguidelines/2015/guidelines/ (accessed July 2020).

2. Office of Disease Prevention and Health Promotion (2020) Healthy people 2020: nutrition and weight status. https:// www.healthypeople.gov/2020/topics-objectives/topic/ nutrition-and-weight-status (accessed July 2020).

3. Eckel RH, Jakicic JM, Ard JD et al. (2014) 2013 AHA/ACC guideline on lifestyle management to reduce cardiovascular risk: a report of the American college of cardiology/American heart association task force on practice guidelines. Circulation 129, S76-S99.
4. USDA (2020) Choose my plate. https://www.choosemy plate.gov (accessed July 2020).

5. USDA \& HHS (2015) Scientific report of the 2015 dietary guidelines advisory committee. https://health.gov/dietary guidelines/2015-scientific-report/pdfs/scientific-report-ofthe-2015-dietary-guidelines-advisory-committee.pdf (accessed July 2020).

6. French SA (2003) Pricing effects on food choices. J Nutr 133, 841S-843S.

7. Bihan H, Castetbon K, Mejean C et al. (2010) Sociodemographic factors and attitudes toward food affordability and health are associated with fruit and vegetable consumption in a low-income French population. J Nutr 140, 823-830.

8. Glanz K, Basil M, Maibach E et al. (1998) Why Americans eat what they do: taste, nutrition, cost, convenience, and weight control concerns as influences on food consumption. J Am Diet Assoc 98, 1118-1126.

9. Andreyeva T, Long MW \& Brownell KD (2010) The impact of food prices on consumption: a systematic review of research on the price elasticity of demand for food. Am J Public Health 100, 216-222.

10. Darmon N, Ferguson EL \& Briend A (2002) A cost constraint alone has adverse effects on food selection and nutrient density: an analysis of human diets by linear programming. J Nutr 132, 3764-3771.

11. Rao M, Afshin A, Singh G et al. (2013) Do healthier foods and diet patterns cost more than less healthy options? A systematic review and meta-analysis. BMJ Open 3 e004277.

12. Fulgoni V 3rd \& Drewnowski A (2019) An economic gap between the recommended healthy food patterns and existing diets of minority groups in the US national health and nutrition examination survey 2013-14. Front Nutr 6, 37

13. Bernstein AM, Bloom DE, Rosner BA et al. (2010) Relation of food cost to healthfulness of diet among US women. Am J Clin Nutr 92 1197-1203.

14. Rehm CD, Monsivais P \& Drewnowski A (2011) The quality and monetary value of diets consumed by adults in the United States. Am J Clin Nutr 94, 1333-1339.

15. Drewnowski A (2010) The cost of U.S. foods as related to their nutritive value. Am J Clin Nutr 92, 1181-1188.

16. Cade J, Upmeier H, Calvert C et al. (1999) Costs of a healthy diet: analysis from the UK women's cohort study. Public Health Nutr 2, 505-512.

17. Hess JM, Cifelli CJ, Agarwal S et al. (2019) Comparing the cost of essential nutrients from different food sources in the American diet using NHANES 2011-2014. Nutr J 18, 68.

18. Centers for Disease Control and Prevention (CDC) \& National Center for Health Statistics (2021) National Health and Nutrition Examination Survey. Hyattsville, MD: National Center for Health Statistics; available at https://www.cdc. gov/nchs/nhanes/index.htm (accessed January 2020).

19. Raper N, Perloff B, Ingwersen L et al. (2004) An overview of USDA's dietary intake data system. J Food Comp Anal 17, 545-555.

20. U.S. Department of Agriculture \& Agricultural Research Service (2018) What we eat in America food categories 2015-2016. www.ars.usda.gov/nea/bhnrc/fsrg (accessed January 2020).

21. U.S. Department of Agriculture \& Agricultural Research Service (2021) USDA food patterns equivalent database. https://www.ars.usda.gov/northeast-area/beltsville-md-bhnrc/ beltsville-human-nutrition-research-center/food-surveysresearch-group/docs/fped-overview/ (accessed January 2020).

22. U.S. Department of Agriculture \& Agricultural Research Service (2018) USDA food and nutrient database for dietary studies. Food surveys research group home page. http:// www.ars.usda.gov/nea/bhnrc/fsrg (accessed January 2020). 
23. Carlson A, Lino M, Juan WY et al. (2008) Development of the CNPP Prices Database. CNPP Reports 45851, USDA, CNPP.

24. U.S. Department of Agriculture (2019) CNPP Data. https://www. fns.usda.gov/resource/cnpp-data (accessed January 2020).

25. U.S. Department of Labor \& Bureau of Labor Statistics (2021) Consumer price index. https://www.bls.gov/cpi/ (accessed January 2020)

26. Monsivais P, Aggarwal A \& Drewnowski A (2012) Are socioeconomic disparities in diet quality explained by diet cost? J Epidemiol Commun Health 66, 530-535.

27. Konttinen H, Sarlio-Lahteenkorva S, Silventoinen $\mathrm{K}$ et al. (2013) Socio-economic disparities in the consumption of vegetables, fruit and energy-dense foods: the role of motive priorities. Public Health Nutr 16, 873-882.

28. Darmon N \& Drewnowski A (2015) Contribution of food prices and diet cost to socioeconomic disparities in diet quality and health: a systematic review and analysis. Nutr Rev 73 643-660.

29. Rehm CD \& Drewnowski A (2016) Dietary and economic effects of eliminating shortfall in fruit intake on nutrient intakes and diet cost. BMC Pediatr 16, 83.

30. Carlson ALM, Juan WY, Hanson K et al. (2006) Thrifty food plan. https://www.cnpp.usda.gov/sites/default/files/usda_ food_plans_cost_of_food/TFP2006Report.pdf (accessed July 2020). 